\title{
A REVIEW TO CAST POLYMER COMPOSITE MATERIALS FOR INTERIOR ENVIRONMENTS
}

UDC: $66.017: 678.7$

Review paper

https://doi.org/10.18485/aeletters.2020.5.1.1

\section{Jasmina Blagojević ${ }^{1,2^{*}}$, Bojan Mijatović ${ }^{1}$, Dejan Kočovićc ${ }^{3}$, Blaža Stojanović2 ${ }^{2}$ Lozica Ivanović2 Sandra Gajević}

${ }^{1}$ Metalac a.d., Metalac Inko d.o.o., Kneza Aleksandra 212, 32300 Gornji Milanovac, Serbia

${ }^{2}$ University of Kragujevac, Faculty of Engineering, Sestre Janjić 6, 34000 Kragujevac, Serbia

${ }^{3}$ Metalac a.d., Metalac Posuđe d.o.o., Kneza Aleksandra 212, 32300 Gornji Milanovac, Serbia

\begin{abstract}
:
The paper provides an overview of mechanical properties the cast polymer composite materials. The polymer composite materials are modern materials respectively advanced composites. The paper presents and explains the most common manufacturing method used, with a brief review on design possibilities in interior environments. The products of these materials are used for equipping the interior environment - kitchen, bathroom, laboratory, etc. It is chemical - resistant materials. Cast polymer composite materials are used for fabricating products that are reliable and meet almost all design criteria, some of the designs solutions are presented in the paper. Modern composites become competitors due to the possibility of modeling different design products. Further research of these materials is carried out in order to improve their mechanical properties.
\end{abstract}

\section{ARTICLE HISTORY}

Received: 02.12.2019. Accepted: 05.03.2020.

Available: 31.03.2020.

\section{KEYWORDS}

Cast polymer composite materials, mechanical properties, manufacturing process, interior environments, design

\section{INTRODUCTION}

The Cast Polymer Composite materials are nonporous low-maintenance material used for surfaces such as countertops, sinks, sanitary ware or sanitary furniture $[1,2]$. It is a composite used to substitute for many indoor household ceramics [3]. Products of The Cast Polymer Composite are distinguished by the materials polymer matrix and type of filler and manufacturing methods used. It is polymer matrix composites materials in which the polymeric matrix is reinforced with particles $[3,4]$.

The material properties of the composite are affected by different parameters, such the size, shape, aspect ratio and distribution of the reinforced particles [5]. These materials differ by type of polymer matrix and type reinforced particle, what will be explained more about in the section on the material.

This group of materials include solid surface materials, engineered stone and engineered composites. The Cast Polymer Composite material is more flexible, and harder than many types of natural stone [6]. It has a uniform internal structure, no hidden cracks or flaws that can exist in natural stone [7]. Polymer matrix is resin. Agents for resin binding allow some flexibility, preventing cracking under flexural pressure. Colour, textures and design flexibility are key factors when choosing engineered composites for large projects.

In this paper there is presented this group of materials, manufacturing process and some of design solutions. Also, in this study presented review of mechanical and chemical properties of materials.

\section{MATERIAL DESCRIPTION}

Products of cast polymer composites can be grouped into three categories: engineered composites, solid surface materials and engineered stone. They are differentiated by the polymer 
matrix materials and manufacturing methods used $[8,9]$.

It is a variety of particle filled composites consisting of thermosetting polymer matrix and particulate reinforcement. The most commonly used resin are unsaturated polyester, acrylic, or polyester modified with acrylic type of resin and most common fillers used are sand, calcium carbonate, alumina trihydrate, and quartz $[4,9,10]$.

\subsection{Engineered composites}

Cultured marble or cultured stone have new name is engineered composites, which introduced by the International Cast Polymer Assn. (ICPA, part of the American Composites Manufacturers Assn., Arlington, Va.) [8]. These materials are composites with matrix of a low-viscosity orthophthalic unsaturated polyester resin and reinforced particles filler calcium carbonate or alumina trihydrate (ATH). In whose composition it is also and pigments. Products which manufactured from these materials contain about $75 \%$ to $78 \%$ filler loading, behind a surface gel coat. A surface gel coat contains UV stabilizers to ensure colour stability and gloss. Application the gel coat obtained a tough, durable, waterproof, non-porous and transparent surface which is very resilient and easy to maintain. Also, glossy surface on the final product are obtained by application gel coat $[8,11]$. Common applications of engineered composites materials are bathroom vanity tops, basins and shower surrounds.

\subsection{Solid surface}

Solid surface products consist of resin and filler also but without a surface gel coat. Solid surface materials are made of polymeric resins including filled acrylic, polyester, and acrylic-polyester blend polymers. The filler is typically alumina trihydrate (ATH) $[8,12,13]$. Solid surface products consist about $50 \%$ to $65 \%$ filler loading.

At solid surface materials use fine ATH filler, and also added pigment. Matrix of this composites material is isophthalic unsaturated polyester resins with UV stabilizers such. Also, can use polymethyl methacrylate (PMMA) thermoset acrylic, or a blend of isophthalic unsaturated polyester and polymethyl methacrylate [8]. Solid surface materials are nonporous and homogeneous. These materials can capable of being repaired, renewed and fabricated into the continuous surface with invisible compound.
At granite-effect products, the fillers are coarser than those used in engineered composites.

Products of solid surface material are used in kitchens, bathroom, hospitals, laboratory and schools, etc.

\subsection{Engineered stone}

Engineered composite stone products made from stone aggregate and synthetic resin matrix materials. It used for production large panels for horizontal or vertical use. Some products mimic natural stone, and some of products can have vibrant artificial in colours [12]. The engineered stone matrix is mostly polyester resin, but it can also be epoxy resin. UV absorbers and stabilizers are added in material. Engineered quartz, polymer concrete and engineered marble stone belong in this category. Materials consist of about $66 \%$ quartz and $34 \%$ resin by volume (90-94 wt. \% of fillers) $[8,14]$. Engineered stone panels usually have polished finishes [12].

For indoor flooring and walls use engineered marbles, and the quartz based product is used primarily for kitchen countertops as an alternative to laminate or granite.

\section{MANUFACTURING PROCESS}

The manufacturing process of products that have a gel coat is called gel coated cultured stone modeling. Gel coat is polyester resin which formulated so provide a cosmetic outer surface on product and gel coat is use to provide water resistance for outdoor products. To the molds surface are applied by spraying the gel coat film. A polyester resin matrix is blended by adding various types of fillers and pigments in to the resin. Mixtures of composites are then transferred to the mold (Fig.1). Then vibration is applied to level and compact the matrix, while the composite is liquid $[15,16]$. Vibration promotes the release of trapped air in the mass. Following polymerized i.e. the cure, the part removed from the mold.

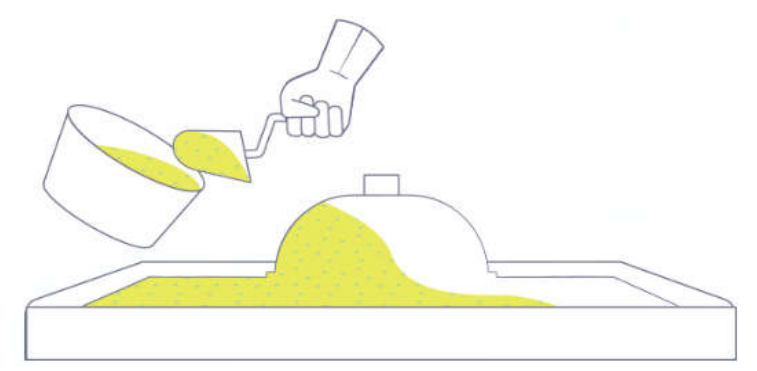

Fig. 1. Gel coated cultured stone modelling $[15,16]$ 
Vacuum-mixing techniques are used for manufacturing solid surface castings (Fig.2). A vacuum is used to remove entrapped air in the matrix. Solid surface parts are homogeneous throughout and surface of these materials is uniform surface that can be cut, sanded, or bonded. Following casting, polymerization and removed from the mold, solid surface casting is post-cured in at elevated temperatures in the furnace. The temperature ranges vary depending on the type of resin and type of filler (generally about $90^{\circ} \mathrm{C}$ ). This way is used to enhance the physical properties of the matrix and produce a stable product.

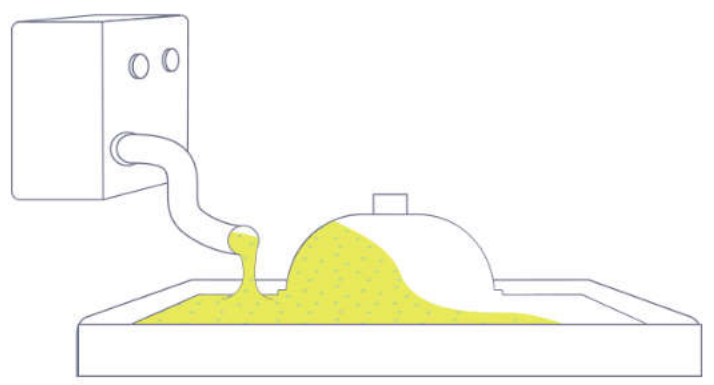

Fig. 2. Solid surface modelling $[15,16]$
Engineered stone with small amount of resin (8 to 15 wt. \%) can be cast into an open-cavity mold and vacuum-assisted press technique can be used to extract air from the matrix and compress it into a low porosity casting. Products with quartz can be manufacturing in the same way, as well solid surface casting.

\section{MECHANICAL AND PHYSICAL PROPERTIES}

Volume fraction or filler concentration, kind of the particles reinforcement, and particle size, shape of the articles and the interfacial adhesion between the matrix and the particles are the major parameters that influence the mechanical properties of the polymer matrix composites reinforcement with particulates [17]. With a larger amount of fillers increase stiffness, fracture toughness, and high temperature load-bearing capability, but decrease shrinkage and improve the appearance of composites products [17-20].

There are differences between products made with acrylic and polyester of resins [21]. Some of the differences are shown in table 1 for the solid surfaces.

Table 1. The differences properties solid surface products made with acrylic and polyester of resins

\begin{tabular}{|c|c|c|c|c|c|c|}
\hline Type resin & $\begin{array}{c}\text { Surface } \\
\text { hardness }\end{array}$ & Colour fastness & $\begin{array}{c}\text { Water } \\
\text { absorption }\end{array}$ & Fire resistant & $\begin{array}{c}\text { Chemical } \\
\text { resistant }\end{array}$ & Heat resistant \\
\hline Acrylic & Good & Better & Better & Good & Good & Good \\
\hline Polyester & Better & Good & Good & Better & Better & Good \\
\hline
\end{tabular}

The filler amount influences the physical and mechanical properties of the product, also of the cost of the product. Lower the costs can be achieved by lowering the resin content in the composition of the particle filled composite [10, 22].

Most important mechanical parameters for brittle materials like polymer composites reinforced particle are surface hardness and flexural strength. Material hardness gives info about material resistance to plastic deformation by scratching, abrasion, or indentation and flexural strength describes the ability of materials to withstand deformation under load. Surface hardness and flexural strength are the most important properties for products, such as bench tops, washbasins, shower trays, wall and floor claddings [10, 23].

In the process manufacturing of thermosetting composites such as the cast polymer composite materials is post cure of the material. Post cure is process in which are raising the composites temperature because of to increase the amount of cross linkage in the composite. The maximum cross-link density is when every carbon to carbon unsaturated group has been reacted and each end group of each chain is connected to another polyester chain. Short post cure times are made possible with ovens that elevate temperatures to the resin's Glass Transition Temperature and higher $[3,10]$.

Only after a successful post cure can be realised dimensional stability, surface hardness and heat resistant of the product. The temperature and the period at which post curing is carried out would depend on the resin type used within the matrix and the thickness of products [21].

Mechanical and physical properties of particulate composite, polymer composites materials reinforced with ATH i.e. solid surface materials was examined in paper [10]. Proportion of filler in materials which used for testing is 50,55 
and $60 \mathrm{wt}$. \%. Test samples were exposed post cure temperature $40^{\circ} \mathrm{C}$ and post cure time $12 \mathrm{~h}$. Samples were tested on hardness, flexural strength, flexural modulus, deflection, and density on materials. It was concluded that flexural strength decreased 3.9MPa, modulus increased $35 \%$, the hardness on Barcol scale increased $5.6 \%$ when $10 \%$ of filler was added. The density also increased $7 \%$ when $10 \%$ filler was added. Concluded was that the cost reduction of the composite was calculated and that decrease in net price for $7.5 \%$.

In paper [5] was examined the mechanical and fracture properties of two different chemical compositions of PMMA. PMMA/Si is stands for poly-methyl methacrylate mixed with a fine dispersion of silica. The composite which tested is suited for sanitary wares that are subjected to severe temperatures. A high temperature leads to failure by cracking in the region near the drain hole. In the paper were analysed the polymer matrix (PMMA) and two composites (Asterite and Amatis) with different volume fraction of filler and different particle size. In table 2 shows the chemical and physical composition of the materials which used for tested. Extensometry data were obtained to the thermal stresses around the drain hole subjected to alternating flow of cold and hot water.

Critical crack lengths were determined from the critical stress intensity factor and maximum local tensile stresses based on measured data. It was estimated to be $1.5 \mathrm{~mm}$ for the Asterite and 4.0 $\mathrm{mm}$ for Amatis composites. Based on testing determined that the Asterite composite with a fine particle size $(10 \mu \mathrm{m})$ presented better mechanical properties (Young's modulus and tensile strength) than the Amatis composite with a coarse particle size $(340 \mu \mathrm{m})$. Important effect of the temperature on stress-strain curves aspects was observed: as the temperature increases both the Young's modulus and the tensile strength decrease while plastic deformation up to rupture increases.

Table 2. Chemical and physical composition of the materials [5]

\begin{tabular}{|c|c|c|c|c|}
\hline \multirow{2}{*}{$\begin{array}{c}\text { Material (trade } \\
\text { mark) }\end{array}$} & \multicolumn{2}{|c|}{ Constituents and volume fraction (\%) } & Particle size $(\boldsymbol{\mu m})$ & Density $\left(\mathrm{g} / \mathrm{cm}^{\mathbf{3}}\right)$ \\
\cline { 2 - 5 } & PMMA & $\mathrm{SiO}_{\mathbf{2}}$ & & \\
\hline Asterite & 44 & 56 & 10 & 1.69 \\
\hline Amatis & 50 & 50 & 350 & 1.74 \\
\hline PMMA & 100 & - & - & 1.2 \\
\hline
\end{tabular}

The mechanical properties of polymer composites reinforced with ceramic particulates were investigated in the paper [17]. The epoxy resin was used, which reinforced with particulate silica with particle size (53-63) $\mu \mathrm{m}$ and alumina with particle size (106-150) $\mu \mathrm{m}$. Fraction of alumina which used is $20 \mathrm{wt}$ \%, $30 \mathrm{wt}$. \% and 40 wt. \% respectively. Specimens were subjected to tensile, compression, bending, impact and hardness tests. It was found that the enhancement in modulus of elasticity is directly proportional to the weight fraction of reinforcement material and that alumina composites have higher modulus of elasticity than silica composites with equivalent weight fraction. The highest modulus of elasticity is that of the composite with $40 \mathrm{wt}$. \% alumina, which is $182 \%$ higher than of the matrix material and the tensile and bending strength of the matrix material were found to be significantly higher than those of the composite material while composites with $30 \mathrm{wt}$. \% and $40 \mathrm{wt}$. \% fraction reinforcement martial have slightly higher compressive strength than the matrix material. Composites reinforced with alumina have significantly higher material toughness, fracture toughness and hardness than that of composites reinforced with equitant silica (quartz) content. The highest material toughness, fracture toughness and hardness are that of the composite with 40 wt. \% alumina.

In paper [24] were examine mechanical properties of polyester resin matrix reinforced with 10 wt. \%, 20 wt. \%, 30 wt. \% and 40 wt. \% of silica particles. The test specimens were subjected to tensile test bending test (three point method), and hardness test. The experimental results he gets indicate that the tensile strength of the matrix material was found to be significantly higher than those of the composite material for $36 \%, 36.1 \%$, $52 \%$ and $57.5 \%$ respectively while the Young's modulus of matrix material was found to be less than of composite material for $14 \%, 33 \%, 42 \%$ and $45 \%$ respectively. Also, test results indicated that the flexural strength of the matrix material were found to be significantly higher than those of the composite material for $6 \%, 27 \%, 29 \%$ and $51 \%$ respectively while the Young's modulus of matrix 
material were found to be less than of composite material for $41 \%, 50 \%, 57.6 \%$ and $63 \%$ respectively. Hardness of the composite materials which tested was significantly higher than the matrix material, and concluded that the enhancements in these properties are proportional to the weight fraction of reinforcement materials. Test results also indicated that the electrical conductivity increased with increasing the silica concentrations.

\section{DESIGN AND APPLICATION FOR INTERIOR ENVIRONMENTS}

Polymer matrix composites materials, advanced composites are designed materials. Properties of the polymer composite materials can be optimized for a specific application due to availability the spectrum of matrix and reinforcement materials available [25].

Solid surface materials are most commonly used in food in food preparation areas [26]. Solid surface materials are used for production counter tops, sinks bathtubs and showers, window sills, floor tiles, stair treads, lighting housings, wall finishes, partitions, and work stations [12].

Fig.3, 4 and 5 shows some of the applications solid surface materials in kitchens, laboratories and bathrooms, respectively.

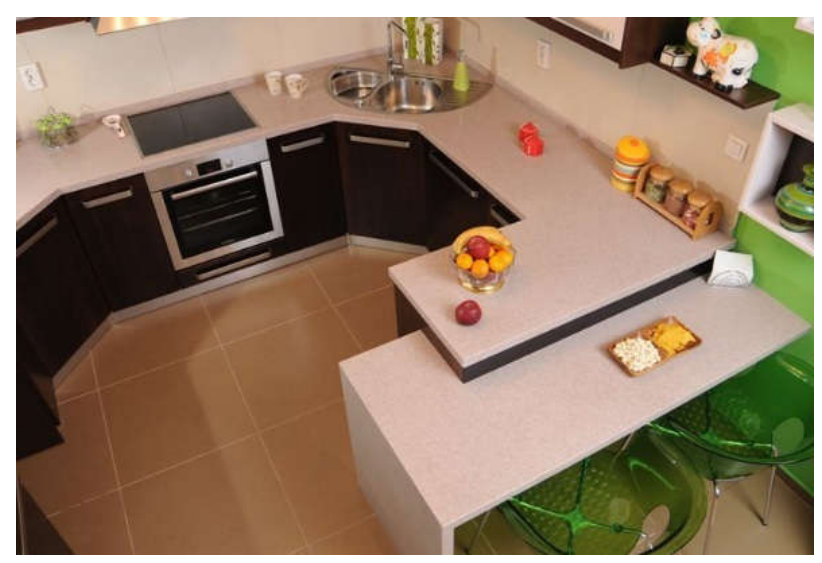

Fig. 3. Applications solid surface materials in kitchens by Metalac INKO $[13,27]$

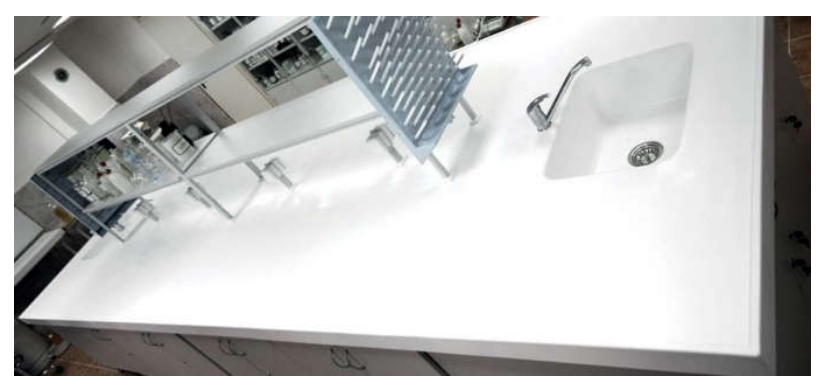

Fig. 4. Applications solid surface materials in laboratories by Metalac INKO [13]

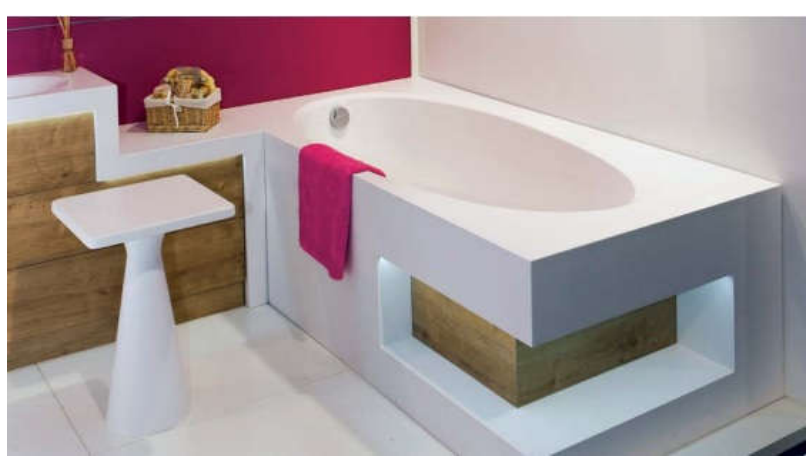

Fig. 5. Applications solid surface materials in bathrooms by Metalac INKO [13]

The engineered stones with very low porosity show very good performance in a large variety of applications that require materials with colour consistency and mechanical strength, as well as maintenance free surfaces. Different engineered stones are available in the market, presenting different compositions, textures and colours [14]. Engineered stone are used for panels for indoor flooring and walls use engineered marbles (Fig.6), and engineered stone the quartz based product is used primarily for kitchen countertops as an alternative to laminate or granite [12]. Engineered stone the quartz based also used for the kitchen sink (Fig.7).

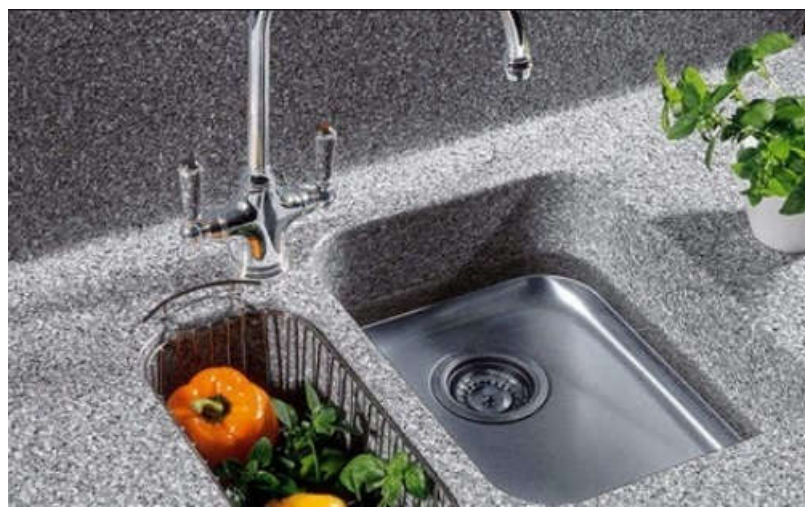

Fig. 6. Applications engineered stone materials for indoor walls and kitchen countertops [28]

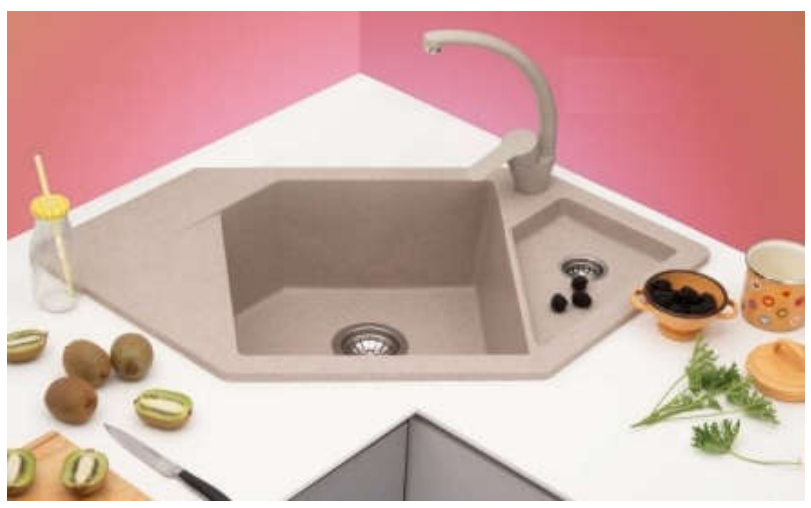

Fig. 7. Applications engineered stone materials for the kitchen sink [27] 
As previously stated, engineered composites with gel coat are used in bathroom vanity, basins and shower surrounds. Some of the applications of engineered composites were shown in Fig.8.

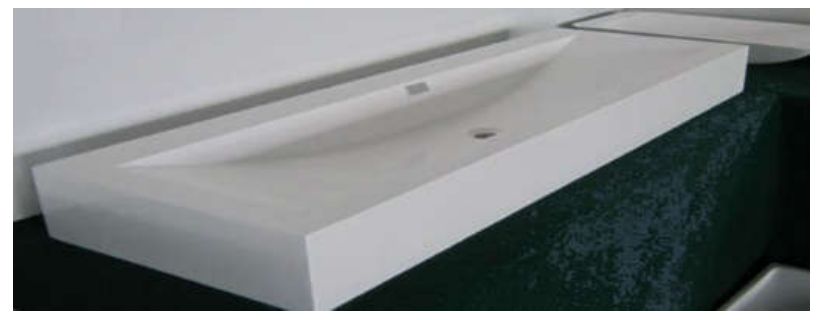

Fig. 8. Applications engineered composites materials with gel coat in bathroom [29]

Cast polymer composite materials are used in interior environments because materials are easy use and care, long lasting, hygienic and good for food contact.

\section{CONCLUSION}

Based on results obtained in different studies for the cast polymer Composite materials certain conclusions can be drawn:

- From the experimental data one can conclude that variations of filler wt. \%, particle size and fraction influences many variables;

- Cast polymer composite materials are increasingly being used in interior environments replace traditional materials. The products of these materials are used for equipping the interior environment - kitchen, bathroom, laboratory, etc., because they are chemical - resistant materials and easy used and cared;

- Color, textures and design flexibility of modern polymer composites materials are key factors when choosing materials for large design projects;

- Further studies should be directed toward examination on the influence of particle physical properties on the mechanical properties of the composite product should be carried out.

\section{ACKNOWLEDGEMENT}

This paper presents the research results obtained within the framework of the projects TR35021, TR35033 financially supported by the Ministry of Education, Science and Technological development of the Republic of Serbia.

\section{REFERENCES}

[1] P. Spielman, The New Scroll Saw Handbook. Sterling Publishing Company, Inc., New York, 2002, pp.297-298.

[2] Creative use of solid surface, https://extremehowto.com/ (Accessed on 15.06. 2019).

[3] K. Lipovsky, Overcoming Vitrification of Polyester Solid Surface Resin for the Kitchen Environment using Postcure, Composites, 2006, pp. 18-20.

[4] M.P. Groover, Fundamentals of modern manufacturing: materials processes, and systems, John Wiley \& Sons, 2007.

[5] J.M. Ferreira, J.D. Costa, C. Capela, Fracture assessment of PMMA/Si kitchen sinks made from acrylic casting dispersion. Theoretical and applied fracture mechanics, 26 (2), 1997: 105-116.

https://doi.org/10.1016/S0167-8442(96)00039-0

[6] What Is the Difference Between Quartz and Quartzite?, Consumer Reports, https://www.consumerreports.org/ (Accessed 10.06.2019).

[7] One-on-One with Sophie Lubin, CONTEMPORARY STONE \& TILE DESIGN, https://www.stoneworld.com/ (Accessed 10.06.2019).

[8] Cast-polymer categories, CompositesWorld, https://www.compositesworld.com/ (Accessed 02.05.2019).

[9] International Cast Polymer Alliance, Solid Surface Properties and Applications. ICPA, Arlington, 2003: 8.

[10] A. Aruniit, J. Kers, K. Tall, Influence of filler proportion on mechanical and physical properties of particulate composite. Agronomy Research, 1, 2011: 23-29.

[11] What is cast polymer?, International Cast Polymer Alliance, https://theicpa.com/ (Accessed 02.05. 2019).

[12] C. Binggeli, Materials for interior environments, $2^{\text {nd }}$ Edition. John Wiley \& Sons, 2013.

[13] Granmatrix, Metalac Inko, https://www.metalacinko.com/ (Accessed 01.05.2019).

[14] J. L. dos Santos, L.G. Rosa, P.M. Amaral, Temperature effects on mechanical behaviour of engineered stones. Construction and Building Materials, 25 (1), 2011: 171-174. 
https://doi.org/10.1016/j.conbuildmat.2010.06.04 $\underline{2}$

[15] Cast polymer molding, American Composites Manufacturers Association, https://discovercomposites.com/ (Accessed 05.05. 2019).

[16] Cast polymer molding, Composites Lab, http://compositeslab.com/ (Accessed 10.06.2019).

[17] A.A. Ibrahim, M.F. Hassan, Study the mechanical properties of epoxy resin reinforced with silica (quartz) and alumina particles. Iraqi journal of mechanical and material engineering, 11 (3), 2011: 486-506.

[18] R.F. Landel, L.E. Nielsen, Mechanical properties of polymers and composites. CRC press, 1993.

[19] Y. Sun, Z. Zhang, C.P. Wong, Influence of interphase and moisture on the dielectric spectroscopy of epoxy/silica composites. Polymer, 46 (7), 2005: 2297-2305.

https://doi.org/10.1016/i.polymer.2005.01.041

[20] J.I. Kim, P.H. Kang, Y.C. Nho, Positive temperature coefficient behavior of polymer composites having a high melting temperature. Journal of Applied Polymer Science, 92(1), 2004: 394-401.

https://doi.org/10.1002/app.20064

[21] Solid Surface Handbook, Chromat, http://www.chromat.com/ 10.06.2019).
[22] M.M. Zurale,S.J. Bhide, Properties of fillers and reinforcing fibers. Mechanics of Composite Materials, 34, 1998: 463-472.

https://doi.org/10.1007/BF02254710

[23] I. Preis, Fatigue Performance and Mechanical Reliability of Cemented Carbides. Tallinn University of Technology Press, 2004.

[24] H.M. Shayma, Studying the Mechanical and Electrical Properties of Polyester Resin Reinforced With Silica Particles. Journal of Engineering and Development, 17 (6), 2013: 201-214.

https://doi.org/10.1007/s12206-017-0213-2

[25] Composites Application guide, Cook Composites \& Polymers, $10^{\text {th }}$ edition, Kansas City, 2005.

[26] J. Postell, N. Gesimondo, Materiality and interior construction. John Wiley \& Sons, 2011.

[27] XGranit, Metalac Inko, https://www.metalacinko.com/ (Accessed 05.05. 2019).

[28] HB Surface, https://www.hbsurface.pl/ (Accessed 10.06. 2019).

[29] OEM kitchen bath Co.,Ltd, http://www.oemproducer.com/ (Accessed 10.06. 2019).

An expanded abstract of this review paper was presented at $" 9^{\text {th }}$ International Scientific Conference IRMES 2019", September 5-7, 2019, Kragujevac, Serbia. 